\title{
Withstanding the test of time: The 1978 semantic word norms
}

\author{
Michael P. Toglia \\ University of North Florida, Jacksonville, Florida
}

\begin{abstract}
This article accompanies the archiving by the Pychonomic Society of the Toglia and Battig (1978) semantic word norms. Herein are outlined the various phases of the project, as well as the challenges that were faced in staying the course during the labor-intensive development of the norms. An examination of the number of citations of this set of norms over the years demonstrates a stable employment of these norms by investigators in many fields. Indeed, a concluding section details the wide range of research topics that have been studied with the use of this extensive set of word ratings. The complete Toglia and Battig article and norms may be downloaded as supplemental materials for this article from brm.psychonomic-journals.org/content/supplemental.
\end{abstract}

In the early 1970s at the University of Colorado, Bill Battig assembled a group of graduate assistants-Michael Toglia, Kay Barrow, Carla Posnansky, and James Pellegrino, who were later joined by Professor Desmond Cartwright - and two energetic undergraduates - Gregory Camilli and Thomas Moore - to engage in the laborintensive project of developing a large set of word norms, laying the foundation for the norms' use in at least 400 subsequent publications across a range of areas, including cognitive psychology, neuroscience, and linguistics. The norms were published by Lawrence Erlbaum in 1978 as the Handbook of Semantic Word Norms and have since been widely referred to as the "Toglia and Battig norms" or the "Colorado norms." "Similarly, the handbook has been cited generally as "Toglia and Battig (1978)."”

Bill Battig was the driving force throughout all of the aspects of this large undertaking, a role he took on cheerfully. In fact, it is interesting to note that the magnitude of this endeavor suited Bill well because he was fond of thinking big when it came to designing studies. Indeed, in referring to Battig's proposal for designing the ultimate factorial experiment to investigate paired-associate learning (Battig, 1968), Tulving and Madigan (1970) tagged his approach as the "intercontinental Battig method" (ICBM).

The ICBM nature of norming such a large set of verbal items was never considered a deterrent by those of us who worked on this project from start to finish. Bill made sure of that! And so it is with great pleasure that I dedicate the archiving of these norms to William F. Battig, who died in June 1979, shortly after their release by Erlbaum.

Readers may wonder why it took 6 years to produce these semantic word norms. Given the technology (or lack thereof) at the time, this was a "blue collar" project that presented many challenges as we faced the enormous task of rating a large number of words (and a few hun- dred nonwords as well!), resulting in 2,854 items scaled on seven dimensions. On the basis of the number of participants contributing data to subsets of the corpus along each dimension, I computed that an estimated 1.2 million individual ratings were provided by our participants. The sheer size of the data sets that contributed to this normative publication was but a by-product of our main objective, which was to provide researchers and practitioners a comprehensive set of verbal items as an alternative in selecting words for their projects at that time. For example, prior to our 1978 norms, a major option was the normative work of Paivio, Yuille, and Madigan (1968). Their norms were, and remain, very useful, but they were limited to 925 items - all nouns - and three scaled dimensions. ${ }^{3}$ The Toglia and Battig norms expanded the rating of verbal items to include many parts of speech and provided data on seven verbal characteristics: imagery, concreteness, meaningfulness, familiarity, number of attributes, categorizability, and pleasantness. Through the years, these semantic norms have frequently been the selected alternative. To this day, the Colorado norms still constitute one of the largest data sets of their kind, providing nearly 20,000 mean ratings.

Perhaps the key factor that kept the production clock ticking was that we were dealing with pre-Scantron technology: Participants rated subsets of items in booklets, resulting in a grandiose paper-and-pencil task. Such a project would be much easier to accomplish now, because subjects would electronically provide responses at computer stations, and the data would be directly imported into Excel files and/or similar software for compilation and analysis. Today's technology surely would have allowed us to complete these semantic word norms within 2 years. The only obstacle that might still have prevented such an optimistic time frame would be the availability, or

M. P. Toglia, m.toglia@unf.edu 
lack thereof, of the over 3,000 participants that we tested in order to produce a stable set of ratings.

But the computer systems of the 1970 s required that we engage in extensive quality-control measures to ensure the high level of accuracy that we were convinced was achieved. The upshot of our vigilance was a publication date of 1978. The Handbook of Semantic Word Norms went out of print after an 8- to 9-year run in 1986. During those years and in the intervening period since 1986, the norms have been used extensively, a conclusion borne out by an inspection of the number of citations of the book (see Table 1). With regard to the compilation of these frequency counts, I am extremely grateful to Daniel Harms, the Coordinator of Instruction Librarian at the State University of New York College at Cortland (my previous institution), who conducted the electronic citation search at a nearby SUNY campus and advised me concerning the shortcomings of such citation searches.

Table 1 displays the number of citations in refereed journals and books, in 5-year blocks. Even a cursory examination of this table reveals the continued usefulness of the norms. These numbers do not reveal the difficulty of getting an accurate count of citations; any search technique has both advantages and drawbacks. For the purposes of constructing this table, Harms conducted a search in late 2007 at the Glenn G. Bartle Library at SUNY Binghamton, using the ISI Web of Science Science Citation Index and Social Sciences Citation Index. In striving not to overlook citations, variant author names and titles were taken into account. Nevertheless, these several hundred citations do not fully capture the scope of the use of the handbook. Non-English publications embody one area in which the count is underrepresented, because the Web of Science misses many cites in these publication venues. ${ }^{4}$ (For an interesting and comprehensive description of these problems, see Meho \& Yang, 2007.)

Also, usage extends beyond what shows up in print; for example, there is the utilization of the Toglia and Battig norms (and other normative works as well) in laboratory courses wherein students conduct demonstration studies and/or original research in cognition, human memory, sensation and perception, experimental psychology, research methods, and psycholinguistics.

Throughout the years, I have received many informal requests to help locate a copy of the norms, and in most cases the request was fulfilled. The archiving of these semantic word norms will make it easy to handle such

Table 1

Citations of Toglia and Battig (1978), in 5-Year Blocks

\begin{tabular}{cc}
\hline 5-Year & $\begin{array}{c}\text { Number of } \\
\text { Citations }\end{array}$ \\
\hline $1978-1982$ & 36 \\
$1983-1987$ & 70 \\
$1988-1992$ & 70 \\
$1993-1997$ & 59 \\
$1998-2002$ & 89 \\
$2003-2007$ & 78 \\
Total & 402 \\
\hline
\end{tabular}

Table 2

Nonexhaustive Set of Topics, Presented Alphabetically, Demonstrating the Broad Use of the 1978 Semantic Word Norms

Clinical populations and cognition

Emotionality/affect of stimuli

Lexical decision making

Linguistic studies

Mood states

Neuroscience, including studies targeting specific areas of the brain

Norms developed after 1978

Perception (e.g., word identification, subliminal)

Priming of memory

Reading research

Self-reference and personality

Semantic memory modeling

Sentence and prose memory

Verbal item memory in many paradigms (e.g., levels of processing, DRM, read-generate)

Verbal item memory in terms of word characteristics (e.g., imagery) and control of confounding word characteristics)

Word vs. pictorial memory (includes picture naming studies)

requests, which will now be fulfilled immediately and, typically, without my involvement. An interesting aspect of these requests was the varied manners in which the requestors planned to make use of the Toglia and Battig norms. Reflecting back on these requests led me to conduct a careful examination of the citations in the search results documented in Table 1, in order to glean just how these norms have been employed. This turned out to be a rather fascinating enterprise, as can be seen in Table 2, where a nonexhaustive list appears. My guess is that the array of usages chronicled in Table 2 is not unique to these norms. Therefore, Table 2 provides a window into the usefulness of normative data, as well as a strong general argument for the archiving of norms. Thus, the placement of the 1978 semantic word norms as a supplement to this article will be, I trust, a very useful addition. One indication of this will manifest itself in what I look forward tonamely, ever-increasing citations of the Colorado norms by researchers and practitioners.

\section{AUTHOR NOTE}

Correspondence concerning this article should be addressed to M. P. Toglia, Department of Psychology, University of North Florida, 1 UNF Drive, Building 51, Jacksonville, FL 32224 (e-mail: m.toglia@unf.edu).

\section{REFERENCES}

BatTig, W. F. (1968). Paired-associate learning. In T. R. Dixon \& D. L. Horton (Eds.), Verbal behavior and general behavior theory (pp. 146171). Englewood Cliffs, NJ: Prentice Hall.

Clark, J. M., \& Paivio, A. (2004). Extensions of the Paivio, Yuille, and Madigan (1968) norms. Behavior Research Methods, Instruments, \& Computers, 36, 371-383.

Meнo, L. I., \& YANG, K. (2007). Impact of data sources on citation counts and rankings of LIS faculty: Web of Science versus Scopus and Google Scholar. Journal of the American Society for Information Science and Technology, 58, 2105-2125.

Paivio, A., Yuille, J. C., \& Madigan, S. A. (1968). Concreteness, imagery, and meaningfulness values for 925 nouns. Journal of Experimental Psychology Monographs, 76, No. 1, Pt. 2. 
Toglia, M. P., \& Battig, W. F. (1978). Handbook of semantic word norms. Hillsdale, NJ: Erlbaum.

Tulving, E., \& Madigan, S. A. (1970). Memory and verbal learning. Annual Review of Psychology, 21, 437-484.

\section{NOTES}

1. Although generally referred to as the Toglia and Battig norms, the front matter of the printed version lists Barrow, Cartwright, Posnansky, Pellegrino, Moore, and Camilli as secondary authors. Such authorship is technically accurate but surely has disguised highly deserved recognition for their important contributions to the resource. Thus I take the opportunity here, reinforcing the credits that Bill and I described in the preface, to once again acknowledge these six individuals, as there was nothing secondary about their significant involvement in this colossal endeavor an its eventual and continuing success as documented in this article. I have always been extremely grateful to these colleagues for their dedication to completing the compilation of these semantic-based ratings.

2. Interestingly, the Spanish journal Psicológica uses the norms for their example of how they wish references to be cited. For books, submit- ters are shown: “- books: Toglia, M. P. y Battig, W. F. (1978). Handbook of semantic word norms. Hillsdale, N.J.: Erlbaum."

3. More than 25 years after the appearance of the Toglia and Battig norms, Clark and Paivio (2004) published an extension of the Paivio et al. (1968) word norms

4. While reading an earlier draft of this article, Harms learned that Web of Science added the Chinese Science Citation Database to their selections. The search he conducted did not include the Chinese Science Citation Database added to Web of Science in December of 2007.

\section{SUPPLEMENTAL MATERIALS}

The original Toglia and Battig (1978) article and norms may be downloaded as supplemental materials for this article from brm.psychonomicjournals.org/content/supplemental.

(Manuscript received August 24, 2008; revision accepted for publication October 6, 2008.) 